\title{
Apatinib-Induced Hand-Foot Skin Reaction in Chinese Patients With Liver Cancer
}

\author{
Hui Xia ${ }^{1+}$, Cheng Zhou ${ }^{1 \dagger}$, Zhaoxia Luo ${ }^{1}$, Ping Zhang ${ }^{2}$, Liping Zhu ${ }^{1 *}$ and Zhao Gong ${ }^{1 *}$ \\ ${ }^{1}$ Department of Hepatobiliary Surgery, Wuhan No. 1 Hospital, Wuhan, China, ${ }^{2}$ Department of Dermatology, Wuhan No. 1 \\ Hospital, Wuhan, China
}

Apatinib, an anti-tumor drug selectively targeting VEGFR2 (Vascular Endothelia Growth Factor Recpetor-2), has been proven effective in Chinese patients with liver cancer. Generally, treatment with apatinib achieves $16.1 \%$ of the overall objective remission rate (ORR) and $55.83 \%$ of the disease control rate (DCR) in Chinese patients with liver cancer. However, the prevalence of apatinib-induced hand-foot skin reaction (Al-HFSR) is noticeably high. The incidence of Al-HFSR is about $50.5 \%$, of which Grades $1 / 2$ and 3 are 38.8 and $11.6 \%$, respectively. In addition, potential molecular mechanisms underlying the development of Al-HFSR are poorly understood and urgently needed to be investigated histologically. In this review, we summarize and review the current efficacy of apatinib and the prevalence of Al-HFSR in Chinese patients with liver cancer. Besides, we postulate the potential mechanisms underlying the development of Al-HFSR and discuss the optimal clinical management for this unwanted cutaneous side effect.

Keywords: apatinib, hand-foot skin reaction, mechanisms, management, Chinese

\section{INTRODUCTION}

Apatinib is a tyrosine kinase inhibitor (TKI) independently developed in China with an IC50 of $1.0 \mathrm{nmol} / \mathrm{L}$. It can efficiently and competitively bind to the intracellular ATP binding site of VEGFR2 (Vascular Endothelial Growth Factor Recpetor-2) protein, thus blocking the downstream signal transduction as well as the migration and proliferation of vascular endothelial cells. As a result, the process of angiogenesis, which is necessary and crucial for tumor growth and progression, is inhibited. VEGFR-2 blockade constitutes the fundamental anti-tumor mechanisms of apatinib. In 2014, apatinib was approved by the Chinese Drug and Food Administration (CDFA) as a second line therapy for advanced gastric cancer or adenocarcinoma of the gastro-esophagus junction.

China has a large number of patients with advanced liver cancer (1). Sorafenib, the traditional and widely-used first-line targeted medication for this disease, is of unsatisfactory benefits and costs extremely high for Chinese patients. Recently, a number of clinical and basic research projects have been funded in China to investigate the potential therapeutic efficacy and clinical complications of apatinib for the treatment of liver cancer. Based on published literatures, however, the prevalence of apatinib-induced HFSR (AI-HFSR) could be as high as $81.8 \%$ (2). In some severe cases, AI-HFSR leads to inevitable withdrawal or interruption of the continuous medication, which may weaken the 
survival benefits of the patients (3). Meanwhile, HFSR shows up as a typical interdisciplinary disease, which usually confuses physicians when handling with it in clinical practice. For these reasons, we here reviewed the literatures for the progress achieved in recent years on various aspects of prevalence, characteristics, diagnosis, mechanisms and treatment of HFSR in Chinese patients with liver cancer.

\section{PREVALENCE OF AI-HFSR IN CHINESE PATIENTS WITH LIVER CANCER}

Although, apatinib has only been approved as the second line of therapy for gastric adenocarcinoma so far in China, its promising effects on the treatment of hepatocellular carcinoma (HCC) have been preliminarily shown in a Phase 2 clinical trial (4). Meanwhile, the performance of conventional chemotherapy for advanced liver cancer still remains unsatisfactory. All these made apatinib standing in the spotlight. Therefore, increasing number of clinical studies have been designed to assess its value in treating liver cancer, which ranks the sixth malignant cancer in the world (5), and the third in China (1). With the accumulation of clinical experiences, however, frequent appearance of AIHFSR during the treatment with apatinib has aroused our intensive concern. In this review, we collected data about the prevalence and clinical outcomes of AI-HFSR in Chinese patients with liver cancer who have received the treatment of apatinib since 2014 .

As shown in Table 1, the incidence of AI-HFSR in Chinese patients with liver cancer is 50.5\% (249/493). After excluding the studies by Zhu et al. (7) and Han et al. (13) (due to the lack of information on AI-HFSR grading), incidence of Grades I/II was $38.8 \%$ (174/448), and 11.6\% (52/448) for Grade III. Actually, the overall incidence rates are slightly higher than that was previously reported in a phase II clinical study (4).

When used as monotherapy, the objective remission rate (ORR) of apatinib was $16.61 \%(47 / 283)$ and the disease control rate (DCR) was $55.83 \%(158 / 283)$. When combined with TACE, the ORR increases to $43.69 \%$ (90/206), and the DCR goes up to $71.3 \%$ (147/206). Of note, apatinib in combination with DebTACE yielded a better outcome, with ORR and DCR reaching 68.8 and $90.6 \%$, respectively, and an overall survival of 22 months.

To better understand AI-HFSR, in our opinion, efforts need to be made to shed more light on two aspects: the detailed molecular mechanisms of apatinib in the anti-tumor treatment of liver cancer; the histological features of AI-HFSR lesions in patients receiving apatinib therapy.

\section{Anti-Tumor Mechanisms of Apatinib in Liver Cancer}

Many studies have been carried out to explore the potential antitumor mechanisms of apatinib. We categorize here the published literatures obtained from the online database on the basis of three aspects (Table 2).

\section{Anti-Tumor Mechanisms in Hepatocellular Carcinoma}

As discussed above, apatinib shows competitive binding to VEGFR-2, thus inhibiting the angiogenesis of vascular endothelium (11). Consequently and logically, impaired

TABLE 1 | Prevalence of Al-HFSR and treatment outcomes of apatinib in chinese patients with liver cancer.

\begin{tabular}{|c|c|c|c|c|c|c|c|c|c|c|c|c|c|}
\hline \multirow[t]{2}{*}{ Author } & \multirow{2}{*}{$\begin{array}{l}\text { Publish } \\
\text { Date }\end{array}$} & \multirow{2}{*}{$\begin{array}{l}\text { Research } \\
\text { Type }\end{array}$} & \multirow[t]{2}{*}{ Stage } & \multirow{2}{*}{$\begin{array}{c}\text { Case } \\
\text { (n) }\end{array}$} & \multirow{2}{*}{$\begin{array}{l}\text { Combined } \\
\text { Therapy }\end{array}$} & \multirow[t]{2}{*}{ Dosage } & \multicolumn{4}{|c|}{ Therapy Outcomes } & \multicolumn{3}{|c|}{ HFSR Incidence (\%) } \\
\hline & & & & & & & $\begin{array}{l}\text { ORR } \\
(\%)\end{array}$ & $\begin{array}{c}\text { DCR } \\
(\%)\end{array}$ & $\begin{array}{c}\text { TTP/ } \\
\text { PFS(m) }\end{array}$ & $\begin{array}{l}\text { OS } \\
(\mathrm{m})\end{array}$ & Total & $\begin{array}{c}\text { Grade } \\
\text { I/II }\end{array}$ & $\begin{array}{c}\text { Grade } \\
\text { III }\end{array}$ \\
\hline \multirow[t]{2}{*}{ Qin et al. (4) } & 2014 & Prospective & Adv & 71 & no & $850 \mathrm{mg}$ & 8.57 & 48.57 & 4.42 & 9.71 & 41.4 & 35.7 & 5.7 \\
\hline & & & & 50 & no & $750 \mathrm{mg}$ & 0 & 37.25 & 3.32 & 9.82 & 29.4 & 21.6 & 7.8 \\
\hline Kou et al. (6) & 2017.1 & Case Report & Adv & 1 & C-TACE + Chemo. & $500 \mathrm{mg}$ & & & & & & & $\sqrt{ }$ \\
\hline Lu et al. (7) & 2017.5 & Prospective & $\mathrm{Mid} / \mathrm{AdV}$ & 20 & c-TACE & $500 \mathrm{mg}$ & 35 & 60 & 12.5 & $\mathrm{~N} / \mathrm{A}$ & 55 & 50 & 5 \\
\hline Kong et al. (8) & 2017.5 & Prospective & Adv & 22 & No & 500 mg/250 mg & 40.9 & 81.8 & 10.4 & $\mathrm{~N} / \mathrm{A}$ & 81.8 & 68.2 & 13.6 \\
\hline Yu et al. (9) & 2018.1 & Prospective & $\mathrm{Mid} / \mathrm{AdV}$ & 31 & No & $500 \mathrm{mg}$ & 32.26 & 80.65 & 4.8 & $\mathrm{~N} / \mathrm{A}$ & 100 & 58.1 & 41.9 \\
\hline Zhen et al. (10) & 2018.3 & Retrospective & $\begin{array}{l}\text { Unresec/ } \\
\text { Recur }\end{array}$ & 32 & No & $\begin{array}{l}250 \mathrm{mg} / 435 \mathrm{mg} / \\
500 \mathrm{mg}\end{array}$ & 16 & 60 & 5 & 13 & 25 & 22 & 3 \\
\hline Yang et al. (11) & 2018.10 & Retrospective & Adv & 25 & c-TACE & $250 \mathrm{mg}$ & 36 & 56 & 4.5 & 16.5 & 68 & 60 & 8 \\
\hline Wang et al. (12) & 2018.11 & Retrospective & $\mathrm{Mid} / \mathrm{AdV}$ & 34 & No & $750 \mathrm{mg}$ & 17.6 & 38.2 & 4.79 & 7.18 & 29.41 & 26.47 & 2.94 \\
\hline Han et al. (13) & 2018.12 & Case Report & Adv & 1 & $\begin{array}{l}\text { c-TACE + OP + } \\
\text { sorafenib }\end{array}$ & $250 \mathrm{mg}$ & & & & 19 & $\sqrt{ }$ & & \\
\hline Yang et al. (14) & 2019.1 & Case Report & Adv & 1 & No & $500 \mathrm{mg}$ & & & 12.5 & $\mathrm{~N} / \mathrm{A}$ & & $\sqrt{ }$ & \\
\hline Zhu et al. (15) & 2019.3 & Prospective & Adv & 44 & C-TACE & $500 \mathrm{mg}$ & 63.64 & 95.4 & 16.5 & $\mathrm{~N} / \mathrm{A}$ & 50 & $\mathrm{~N} / \mathrm{A}$ & $\mathrm{N} / \mathrm{A}$ \\
\hline Fan et al. (16) & 2019.4 & Retrospective & Adv. & 85 & C-TACE & $500 \mathrm{mg}$ & 28.2 & 58.7 & 6.1 & 12 & 52.9 & 29.4 & 23.5 \\
\hline Zhang et al. (17) & 2019.5 & Case Report & Recur & 1 & Camrelizumab & $250 \mathrm{mg}$ & & & & & & $\sqrt{ }$ & \\
\hline Liu et al. (18) & 2019.7 & Prospective & $\mathrm{Mid} / \mathrm{AdV}$ & 32 & Deb-TACE & 500 mg & 68.8 & 90.6 & 9.5 & 22 & 28.1 & 28.1 & 0 \\
\hline Zhang et al. (17) & 2019.7 & Retrospective & Adv & 43 & No & 500 mg & 25.6 & 67.4 & 3 & 8 & 74.4 & 69.8 & 4.7 \\
\hline
\end{tabular}

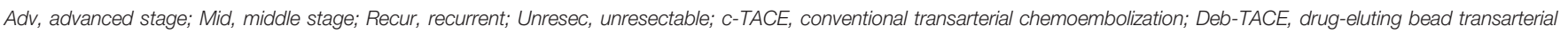
chemoembolization; ORR, objective remission rate; DCR, Disease Control Rate; TTP, Time to Progress; PFS, Progress Free Time; OS, Overall Survival. 
TABLE 2 | Pathways underlying the anticarcinogenic effect of apatinib on liver cancer.

\begin{tabular}{|c|c|c|c|c|c|}
\hline Author & $\begin{array}{l}\text { Publish } \\
\text { Date }\end{array}$ & Journal & Pathway & Vitro & Vivo \\
\hline $\begin{array}{l}\text { Peng et al. } \\
\text { (19) }\end{array}$ & 2016.3 & Oncotarget & $\mathrm{PI}$ IK/AKT/mTOR & CCA: RBE, SSP25 & $\mathrm{RBE}$ \\
\hline $\begin{array}{l}\text { Jiang et al. } \\
(20)\end{array}$ & 2016.8 & Chin J Clin Pharmacol & P53, Caspase-3, Caspase-8 & HCC: HepG2 & \\
\hline $\begin{array}{l}\text { Wen et al. } \\
(21)\end{array}$ & 2018.1 & Pathol Res Pract & STAT3, BAX/Bcl-2 & HCC: SMCC-7721 & \\
\hline $\begin{array}{l}\text { Zhang et al. } \\
\text { (22) }\end{array}$ & 2018.1 & Oncol Lett & PI3K/AKT & HCC: SMCC-7721, Bax, Caspase-9, Bcl-2 & \\
\hline Li et al. (23) & 2018.2 & $\begin{array}{l}\text { Biochim Biophys Acta Mol } \\
\text { Basis Dis }\end{array}$ & PDGFR- $\alpha$, IGF-IR & $\begin{array}{l}\text { CCA: HCCC-9810; HCC: Huh-7, Li-7, BEL-7402, Hep3b, } \\
\text { HepG2 }\end{array}$ & Hep3b \\
\hline $\begin{array}{l}\text { Yang et al. } \\
(11)\end{array}$ & 2018.6 & Cancer Med & $\mathrm{AKT}, \mathrm{ERK} 1 / 2, \mathrm{G} 2 / \mathrm{M}$ & $\begin{array}{l}\text { HCC: SK-Hep-1, HepG2, Hep3B, Huh-7, PLC/PRF/5, } \\
\text { SMMC-7721; EC: HUVEC }\end{array}$ & $\begin{array}{l}\text { PLC/PRF/5,SK- } \\
\text { Hep-1 }\end{array}$ \\
\hline $\begin{array}{l}\text { Huang et al. } \\
\text { (24) }\end{array}$ & 2018.11 & BMC Gastroenterol & RAF/MEK/ERK, PI3K/AKT & CCA: QBC939, TFK-1 & \\
\hline $\begin{array}{l}\text { Gu et al. } \\
(25)\end{array}$ & 2019.6 & $\mathrm{~J}$ Cell Biochem & $\begin{array}{l}\text { Pyruvate, Alanine, Aspartate, } \\
\text { Glutamate }\end{array}$ & HCC: HepG2 & \\
\hline $\begin{array}{l}\text { Feng et al. } \\
(26)\end{array}$ & 2019.8 & Cancer Sci & PPAR $\alpha, 3-\mathrm{HB}$ & HCC: HepG2 & A549 \\
\hline $\begin{array}{l}\text { Liao et al. } \\
(27)\end{array}$ & 2019.11 & J Exp Clin Cancer Res & PI3K/AKT & HCC: SMMC-7721, MHCC-97H, HCCLM3, Hep-3B & SMMC-7721 \\
\hline
\end{tabular}

CCA, Cholangiocarcinoma; HCC, Hepatocellular Carcinoma.

angiogenesis leads to tumor suppression. Several studies have shown that apatinib can also functionally suppress the STAT3, ERK1/2, and PI3K/AKT pathways $(11,22-24,28)$, downregulate the expression of pro-survival mediators of PDGF $\alpha$, IGF-IR, and $\mathrm{Bcl}-2(22,23,28)$, and upregulate the expression of pro-apoptotic genes of Bax, p53, and Caspases 3, 8, and 9 (20, 22). Through these mechanisms, apatinib exerts its anti-tumor activity through promoting the apoptosis of hepatic tumor cells. Furthermore, apatinib has also been demonstrated to be able to arrest the proliferating cancer cells at the G2/M cell cycle stage (11), and promote the vascular normalization of tumors, thus enhancing the sensitivity of radiotherapy for HCC (27).

\section{Anti-Tumor Mechanisms in Cholangiocarcinoma}

Huang et al. (24) showed that apatinib could suppress migration and invasion of CCA cells through inhibiting the RFA/MEK/ ERK and PI3K/AKT signaling pathways. The study by Peng et al. (19) also showed that apatinib could inhibit the anti-apoptosis pathway of PI3K/AKT/mTOR signaling to promote the cellular death of CCA cells in vitro.

\section{Metabolism Regulation of Apatinib in Liver Cancer}

Recently, researchers found that apatinib could also regulate the metabolic functions of liver cancer cells. For instance, Gu et al. (25) reported that apatinib reduces the intake of pyruvate, and retards the secretion of lactate in HepG2 cells. According to Feng's study (26), apatinib has been demonstrated to enhance the synthesis of 3-hydroxybutyric acid (3HB), a metabolites inhibiting tumor growth both in vitro and in vivo, through activation of PPAR $\alpha$ and promotion of fatty acid utilization. These recent studies provided clues to potential mechanism of metabolism regulation underlying the antitumor effect of apatinib besides its anti-angiogenic effect.

\section{HISTOLOGY OF HFSR}

To the best of our knowledge, there are no studies elucidating the histological characteristics of AI-HFSR lesions. Reports on TKIinduced HFSR are also relatively lacking. Because of this, we referred to the histological data related to other TKIs, such as sorafenib, sunitinib, regorafenib etc. Based on the criteria of classification for HFSR which was proposed by the NCI (National Cancer Institute), the severity of HFSR is graded into three levels. The features of TKI-induced HFSR include: 1. Increased epidermal proliferation (papillomatosis, acanthosis); 2. Keratinocyte necrosis (eosinophilic body, vacuolar degeneration, confluent keratinocyte necrosis, and intraepidermal cleavage); 3. Keratinocyte over-proliferation (parakeratosis, retention of pyknotic nuclei). These characteristics are usually different from the chemotherapeutic drugs-induced HFS (Hand-Foot Syndrome), which is mainly manifested by necrosis of epithelial cells and injury of eccrine sweat glands.

Although modifications have been made on CTCAE version 3.0 (29) to make it more accurately in line with clinical practice, the histological description of HFSR in version 4.03 (30) is still incomplete and lacking in details. In 2009, Yang et al. (31) performed histological examination on eight cases of sorafenibinduced HFSR. They found eosinophilic bodies emerged in $80 \%$ of the samples. They explained the observed pathological changes as a secondary consequence to keratinocyte necrosis. The typical manifestation of HFSR is apoptosis of keratinocytes and satellitosis of lymphocytes. Besides, emergence of cavernous lesions and lack of neutrophilic infiltration, which resembles the 
histological features of immune response-mediated skin lesions, was also observed in HFSR (32). Despite of diverse characteristics, previous reports consistently found that lack of granulocytes infiltration and increased accumulation of lymphocytes in the dermis of skin occurs frequently during the development of HFSR $(31,33)$. In 2019, however, Sirka et al. (34) reported a grade III case of HFSR displaying a different histological signature. The results of biopsy discovered plenty of bullae within the stratum corneum and exuberant infiltration of neutrophils and fibrin, which was different from other reports. This implies that, in severe cases, neutrophils might be recruited when concomitant bacterial infection occurs. All in all, future histopathological studies are still needed to shed a deep insight into the features of TKI-induced HFSR.

\section{Potential Mechanisms Underlying Al-HFSR}

Although the mechanism of HFSR remains poorly understood, several recognitions can be conceivably acquired: First, like other TKIs, AI-HFSR usually occurs in a dose-dependent manner which indicates that the development of AI-HFSR is not because of allergic reaction (35). Second, it is known that, chemotherapeutic drugs can be excreted via the eccrine sweat glands, through which exerting its toxic injury to the skin during the development of HFS. However, similar as TKIs like sorafenib, which is lipophilic and has been demonstrated to be undetectable from the sweat glands (36), apatinib-induced HFSR probably maintains a different mechanism of pathogenesis from that of chemotherapeutic drugs-induced HFS. Third, Bevzcizumab, a recombinant humanized anti-IgG1 antibody against VEGF, does not give rise to HFSR when used as monotherapy for patients (37). This implies that inhibition of VEGF/VEGFR signaling is not the main cause of apatinib-induced cutaneous side effects. Therefore, mechanisms presiding over the AI-HFSR seem to be a group of pathogenic factors.

Under physiological conditions, body parts, such as the fingers, palms, and soles, bear continuous pressure or frequent impact. In other words, they suffer from so called "subclinical trauma" (38). Chronic and persistent trauma requires constant tissue repair. However, following treatment with TKIs, the regenerative ability is compromised. VEGFR and PDGFR are suppressed by the TKIs, resulting in peripheral vascular endothelium dysfunction (33). Therefore, the capacity of cutaneous self-healing is severely impeded $(39,40)$. Histological investigation on HFSR shows massive keratinocytic apoptosis, perivascular lymphocytic infiltration, interface dermatitis without neutrophils participation, basilar vacuolar degeneration, and dyskeratosis. This supports the possibility of direct cytotoxic injury (41). Thus, the prevalence hypothesis is that HFSR is caused by drug extravasation from impaired dermic capillaries due to subclinical trauma. However, experimental evidence showing high concentration of apatinib in the skin of palms or soles is still missing.

Histologically, the coexistence of over proliferation and extensive necrosis in keratinocytes is a prominent feature of AI-HFSR. This brings up two questions that need to be answered.

First, does TKI directly promote proliferation of keratinocytes? On the contrary, clinical practice demonstrated that topical application of sunitinib could efficiently alleviate the keratosis of skin lesions in patients with psoriasis. Mechanically, Ye et al. (42) showed that sunitinib inhibits keratinocyte proliferation by reducing the pSTAT3 activity. Under physiological conditions, skin areas that are frequently exposed to continuous stress or friction prefer to form callus through keratinocyte hyperproliferation. The formed callus defensively disperse the pressure on this area and protect the deeper tissue from mechanical injury (43). Therefore, for AI-HFSR, possible mechanisms can be conceived that high dose usage of apatinib exerts an inhibitory effect on VEGFR/PDGFR, thus hindering the self-repair of the cutaneous tissues. As a result, damages caused by subclinical trauma will persist for the existence of handicapped regeneration induced by apatinib. This will subsequently provoke the proliferation of keratinocytes, thereby giving rise to the development of AI-HFSR. Furthermore, since the speed of cell proliferation has been significantly accelerated, there is not enough time for the proliferating keratinocytes to fully differentiate and become mature. Consequently, part of the regenerated keratinocytes is incompletely differentiated, and thereafter parakeratosis or dyskeratosis occurs (43-45). All the characteristics mentioned above are actually consistent with the histologic manifestations of AI-HFSR.

The second question is, in which pathway the TKIs lead keratinocytes to apoptosis? The papers by Zeng et al. (46) and Li et al. (47) confirmed that blocking the ERK1/2 signaling pathway in $\mathrm{HaCaT}$, a human keratinocyte cell line, significantly retarded the inflammatory reaction of these cells in vitro. Meanwhile, experiments with apatinib showed that, high dose administration of apatinib exactly exert an inhibitory effect on ERK1/2 signaling activation (48). As such, apoptosis of keratinocytes is probably not mediated through the activation of ERK1/2 pathway and their associated inflammatory injury. Preclinical pharmacokinetic study indicated that sorafenib has a longer half-time in the skin $(72.8 \mathrm{~h})$, when compared with in other organs (20-36 h) (49). Eric et al. (50) found that keratinocytes uptake sorafenib by membrane transporter OAT6 (Organic Anion Transporter 6). The intracellularly transported sorafenib then targets MAP3K7 (Mitogen-activated Protein Kinase 3K7) and causes keratinocyte apoptosis. Another study also showed that inactivation of TAK1 (MAP3K7) was able to increase the accumulation of ROS (Reactive Oxygen Species) partly through c-Jun signaling pathway, by which inducing keratinocyte apoptosis (51). However, whether or not the OAT6-mediated drug transportation or the TAK1-c-Jun-ROS axis-regulated apoptosis also play a role in regulating the keratinocyte injury of AI-HFSR is worth interrogating in future studies.

In conclusion, persistent existence of subclinical trauma, impaired vascular function and TKIs-induced keratinocyte apoptosis, are contributing factors collectively facilitating the development of AI-HFSR. The TKIs extravasated from damaged capillary vessels caused by persistent subclinical trauma impede the regeneration of endothelium per ERK1/2 or P-STAT3 pathway, and lead to the deterioration of capillary injury and extravasation. Although, TKIs has directly inhibitive effects on proliferation of keratinocyte by P-STAT3 signal path, but its' strength is far more weaker than the opponent promoting effect derived from the persistent subclinical trauma, therefore, the keratinocytes present 
over proliferation in HFSR as the result. In addition, through the TAK1 and C-JUN/ROS pathway, TKIs could also promote the apoptosis of keratinocytes. Therefore, the injuries of capillary, over proliferation and apoptosis of keratinocytes compose the characteristic histology manifestations, which are very informative for the explanation of the underlying mechanism in HFSR. The model of AI-HFSR was showed in Figure 1.

\section{Treatment of Al-HFSR}

Due to the lack of clinical trials or investigations, evidence-based approaches of the optimized treatment for HFSR are still missing (52). Therefore, clinical management of targeted therapyinduced HFSR was suggested to take an individualized and multidisciplinary treatment measures (53).

\section{Patient's Education and Guidance}

Education and guidance for patients with skin side effects in their daily actives is an important aspect for HFSR management that cannot be overlooked. The specific measures include manicure, pedicure, removal of hyperkeratotic skin, and proper handling of eczema and fungal infection before receiving the treatment of apatinib. During the course of therapy, much attention should be paid to the skin care by using alcohol-free moisturizer, avoiding direct contact from hot water (e.g. bath, dish washing), wearing no over-tight garments, minimizing the incidence of exposing to friction (e.g. typing, massage), avoiding excessive physical activities, equipping insole cushions and thick socks and maintaining good personal hygiene.

\section{Apatinib Reduction and Withdrawal}

For HFSR treatment, reduction and withdrawal of apatinib has always been a difficult choice (54). As the CTCAE protocols (30) recommend: For patients with grade I HFSR, continuous administration of apatinib is acceptable with a two weeks' followup visit; For grade II HFSR, treatment with a reduced dosage of apatinib for 7-28 days with timely monitoring is recommended; For grade III HFSR, withdrawal of the medication for at least seven days is recommended, for the purpose of recovering from the toxic reaction to the expected end point of grade I or II.

\section{Medications Moisturizers}

In Shinohara's report (55), a hydrocolloid dressing containing ceramide with a low-friction external surface was shown to function as a strong skin-protecting cushion through reducing skin friction, buffering $\mathrm{pH}$, and shielding the skin from bacterial. As a result, it effectively relieved the pain caused by HFSR, and prevented the progressing of HFSR towards higher grades.

\section{Keratolytic Agents}

In China, research by Ai et al. (56) recruited 871 cases, the largest HFSR trial so far, to assess the prophylactic effect of urea cream,

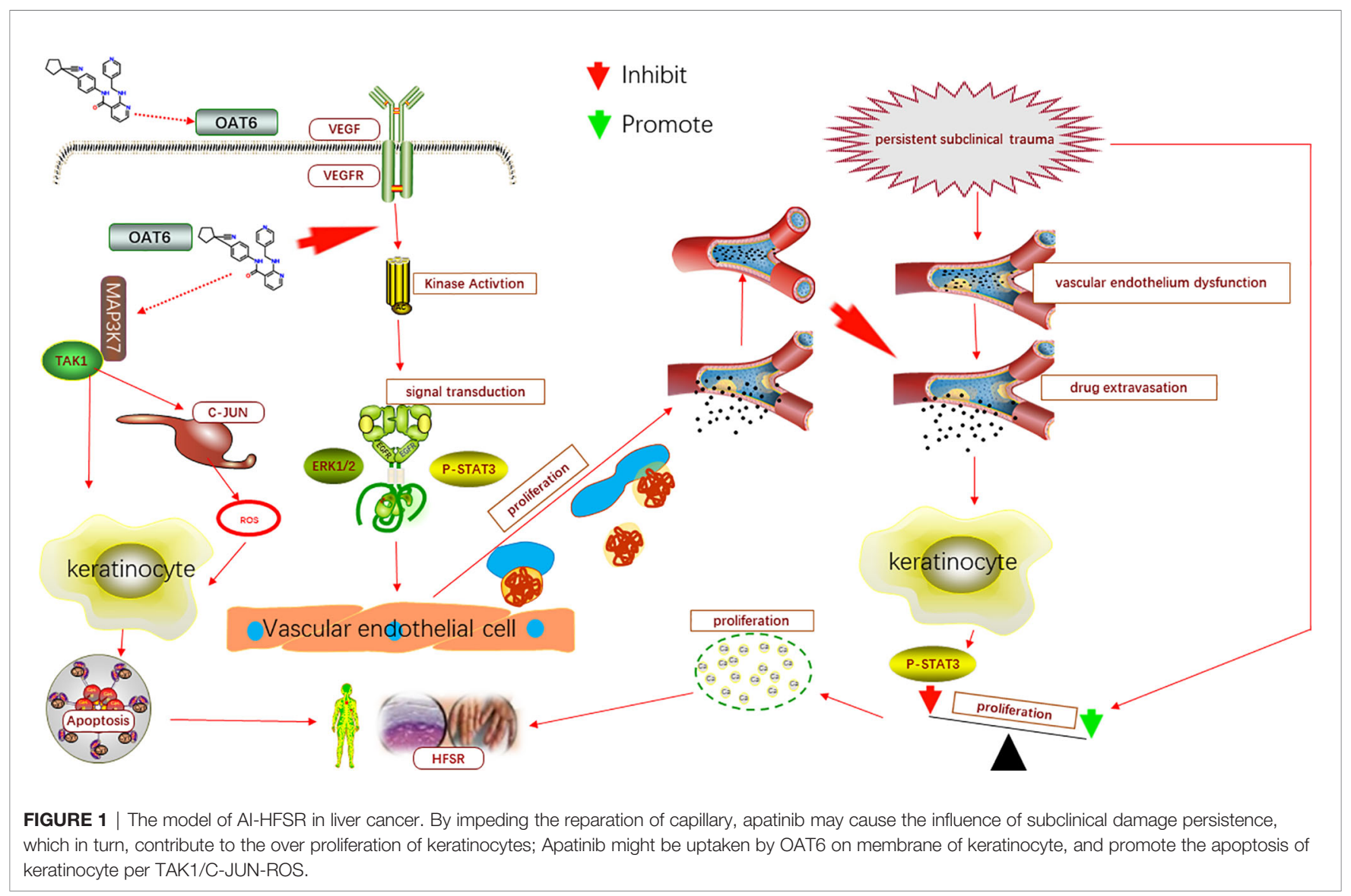


combined with the best supportive therapy (BCS), on HFSR. Their results show that such a combination therapy significantly delayed the first onset of HFSR. Similarly, another clinical study that has been carried out in the Guro Hospital of Korea University, is aimed to evaluate the clinical value of urea cream application in treating patients with sorafenib-associated HFSR (57). The outcomes, however, have not been achieved yet.

\section{Anti-Proliferation Agents}

Previous study has demonstrated that tazarotene can greatly upregulate the expression of TIG-1 (Tazaroten-Induced Gene-1), a trans-membranal protein functioning as a cellular adhesion molecule that may promote cell-to-cell contact, thereby reducing keratinocyte proliferation (58). Moreover, a Japanese doctor, Yamamoto (59), is now leading a clinical study that aims to put forward the application of ascorbyl-2-phosphate magnesium (P-VC-Mg), a cosmetic product, for the treatment of HFSR. Although no results were available yet, his preliminary experimental data (60) have indicated that this highly permeable ascorbic acid derivative could confront against sorafenib-induced hyperproliferation of keratinocytes in a $3 \mathrm{D}$ skin model.

\section{Traditional Chinese Medicine}

Studies by Tian et al. (61) and Zhao et al. (62) demonstrated the efficacy of handling HFSR by successive treatment with the traditional Chinese medications, Danxiong granules and Taohongsiwu. In 2020, Wang et al. (63) reported in a prospective randomized clinical trial study that topical soaking with LC09, a compound granules consisting of Astragali Radix, Angelicae Sinensis Radix, Erodii Herba, Geranii Herba, Arnebiae Radix, and Carthami Flos, could effectively alleviate pain and reduce the severity of HFSR. Moreover, in most cases, the effectiveness of LC09 granules could be achieved within seven days.

\section{Other Medications}

It has been proved that $\beta$-hydroxy- $\beta$-methylbutyrate (HMB), Larginine, and L-glutamine could promote collagen synthesis in the process of wound healing. Recently, Naganuma et al. (64)

\section{REFERENCES}

1. Chen W, Zheng R, Baade PD, Zhang S, Zeng H, Bray F, et al. Cancer statistics in China, 2015. CA Cancer J Clin (2016) 66:115-32. doi: 10.3322/ caac. 21338

2. Tian S, Quan H, Xie C, Guo H, Lu F, Xu Y, et al. YN968D1 is a novel and selective inhibitor of vascular endothelial growth factor receptor-2 tyrosine kinase with potent activity in vitro and in vivo. Cancer Sci (2011) 102:137480. doi: 10.1111/j.1349-7006.2011.01939.x

3. Chanprapaph K, Rutnin S, Vachiramon V. Multikinase Inhibitor-Induced Hand-Foot Skin Reaction A Review of Clinical Presentation, Pathogenesis and Management. Am J Clin Dermatol (2016) 17:387-402. doi: 10.1007/ s40257-016-0197-1

4. Qin SK, OuYang XN, Bai YX, Cheng Y, Xu JM, Li J, et al. Multicenter Phase 2 study of apatinib, a novel inhibitor of VEGFR, in patients with advanced hepatocellular carcinoma. In: Asco Meeting Abstracts, vol. 32. (2014). doi: 10.1200/jco.2014.32.15_suppl.4019

5. Bray F, Ferlay J, Soerjomataram I, Siegel RL, Torre LA, Jemal A. Global cancer statistics 2018: globocan estimates of incidence and mortality worldwide for found that prophylactic administration of an ONS (oral nutritional supplement) containing these ingredients before the initiation of sorafenib treatment could effectively decrease the incidence of HFSR. Other possible medications include analgesics (e.g. lidocaine gel, NSAIDs, GABA agonists) and corticosteroid (e.g. clobetasol).

\section{PERSPECTIVE}

Apatinib is a newly developed TKI in China. A growing body of studies has validated its clinical efficacy in patients with liver cancer. We believe that, with the forthcoming data of the Phase III study in Chinese patients with liver cancer and a satisfactory cost-effectiveness, extended indications of apatinib approved by the CDFA for targeted therapy of liver cancer can be expected in the near future. Undoubtedly, apatinib will have a great potential in the field of targeting liver cancer in China. Hence, in-depth understanding and optimal clinical management of AI-HFSR, the most common complication of apatinib administration, will always be a challenge for not only hepatologists, but also oncologists, dermatologists, and multidisciplinary teams.

\section{AUTHOR CONTRIBUTIONS}

All authors provided substantial contribution to the conception, drafting, editing, and final approval of this manuscript. All authors contributed to the article and approved the submitted version.

\section{FUNDING}

This work were supported by the Chen Xiao-ping Foundation for the Development of Science and Technology of Hubei Provincial (CXPJJH11800001-2018203) and National Natural Science Foundation of China (Grant No.81803157).

36 cancers in 185 countries. CA Cancer J Clin (2018) 68:394-424. doi: $10.3322 /$ caac. 21492

6. Kou P, Zhang Y, Shao W, Zhu H, Zhang J, Wang H, et al. Significant efficacy and well safety of apatinib in an advanced liver cancer patient: a case report and literature review. Oncotarget (2017) 8(20510-20515). doi: 10.18632/ oncotarget.14724

7. Lu W, Jin XL, Yang C, Du P, Jiang FQ, Ma JP, et al. Comparison of efficacy between TACE combined with apatinib and TACE alone in the treatment of intermediate and advanced hepatocellular carcinoma: A single-center randomized controlled trial. Cancer Biol Ther (2017) 18:433-8. doi: 10.1080/15384047.2017.1323589

8. Kong YL, Sun L, Hou ZY, Zhang YQ, Chen P, Cui YL, et al. Apatinib is effective for treatment of advanced hepatocellular carcinoma. Oncotarget (2017) 8(62):105596-605. doi: 10.18632/oncotarget.22337

9. Yu WC, Zhang KZ, Chen SG, Liu WF. Efficacy and Safety of apatinib in patients with intermediate/advanced hepatocellular carcinoma: A prospective observation study. Med (Baltimore). (2018) 97(3):e9704. doi: 10.1097/ MD.0000000000009704

10. Zhen L, Jiali C, Yong F, Han X, Hongming P, Weidong H. The Efficacy and Safety of Apatinib Treatment for Patients with Unresectable or Relapsed Liver 
Cancer: a retrospective study. J Cancer. (2018) 9(16):2773-7. doi: 10.7150/ jca. 26376

11. Yang Z, Chen G, Cui Y, Xiao G, Su T, Yu J, et al. The safety and efficacy of TACE combined with apatinib on patients with advanced hepatocellular carcinoma: a retrospective study. Cancer Biol Ther (2019) 20(3):321-7. doi: 10.1080/15384047.2018.1529099

12. Wang Y, Gou Q, Xu R, Chen X, Zhou Z. Efficacy and safety of sorafenib versus apatinib in the treatment of intermediate and advanced hepatocellular carcinoma: a comparative retrospective study. OncoTargets Ther (2018) 11:3407-13. doi: 10.2147/OTT.S161023

13. Han Z, He Z, Wang C, Wang Q. The effect of apatinib in the treatment of sorafenib resistant metastatic hepatocellular carcinoma: A case report. Med (Baltimore) (2018) 97:e13388. doi: 10.1097/MD.0000000000013388

14. Yang $\mathrm{X}, \mathrm{Wu} \mathrm{G}, \mathrm{Xu}$ G. Apatinib treatment of advanced hepatocellular carcinoma with portal vein and inferior vena cava tumor thrombus. Medicine (2019) 98(8):e14582.

15. Zhu Y, Feng B, Mei L, Sun R, Guo C, Zhu J. Clinical efficacy of TACE combined with Apatinib in the treatment of advanced hepatocellular carcinoma. JBUON (2019) 24(2):608-14.

16. Fan W, Yuan G, Fan H, Li F, Wu Y, Zhao Y, et al. Apatinib Combined With Transarterial Chemoembolization in Patients With Hepatocellular Carcinoma and Portal Vein Tumor Thrombus: A Multicenter Retrospective Study. Clin Ther (2019) 41(8):1463-76. doi: 10.1016/j.clinthera.2019.04.036

17. Zhang Y, Fan W, Wang Y, Huang G, Li J. Apatinib for Patients With Sorafenib-Refractory Advanced Hepatitis B Virus Related Hepatocellular Carcinoma: Results of a Pilot Study. Cancer Control. (2019) 26 (1):1073274819872216. doi: 10.1177/1073274819872216

18. Liu J, Xu J, Zhang W, Chen J, Zhou X, Li Z, et al. Safety and Efficacy of DrugEluting Bead Transarterial Chemoembolization Combined with Apatinib in Patients with Advanced Hepatocellular Carcinoma. Acad Radiol (2019). doi: 10.1016/j.acra.2019.07.003

19. Peng H, Zhang Q, Li J, Zhang N, Hua Y, Xu L, et al. Apatinib inhibits VEGF signaling and promotes apoptosis in intrahepatic cholangiocarcinoma. Oncotarget (2016) 7:1-10. doi: 10.18632/oncotarget.7948

20. Jiang ZK, Ye XG, Chen QH. Effect of apatinib on the proliferation and migration of liver cancer cells. Chin J Clin Pharmacol (2016) 32:1422-4. doi: 10.13699/j.cnki.1001-6821.2016.15.023

21. Wen S, Shao G, Zheng J, Zeng H, Luo J, Gu D. Apatinib regulates the cell proliferation and apoptosis of liver cancer by regulation of VEGFR2/STAT3 signaling. Pathol - Res Pract (2019) 215(4):816-21. doi: 10.1016/j.prp.2019. 01.021

22. Zhang H, Cao Y, Chen Y, Li G, Yu H. Apatinib promotes apoptosis of the SMMC-7721 hepatocellular carcinoma cell line via the PI3K/Akt pathway. Oncol Lett (2018) 15:5739-43. doi: 10.3892/ol.2018.8031

23. Li X, Xu A, Li H, Zhang B, Cao B, Huang J. Novel role of apatinib as a multitarget RTK inhibitor in the direct suppression of hepatocellular carcinoma cells. Biochim Biophys Acta (BBA) - Mol Basis Dis (2018) 1864:1693-701. doi: 10.1016/j.bbadis.2018.02.014

24. Huang M, Huang B, Li G, Zeng S. Apatinib affect VEGF-mediated cell proliferation, migration, invasion via blocking VEGFR2/RAF/MEK/ERK and PI3K/AKT pathways in cholangiocarcinoma cell. BMC Gastroenterol (2018) 18:169. doi: 10.1186/s12876-018-0870-3

25. Gu J, Shu D, Su F, Xie Y, Liang X. Analysis of metabolome changes in the HepG2 cells of apatinib treatment by using the NMR-based metabolomics. J Cell Biochem (2019) 120:19137-46. doi: 10.1002/jcb.29242

26. Feng S, Wang H, Wang Y, Sun R, Xie Y, Zhou Z, et al. Apatinib induces 3hydroxybutyric acid production in the liver of mice by peroxisome proliferator-activated receptor alpha activation to aid its antitumor effect. Cancer Sci (2019) 110:3328-39. doi: 10.1111/cas.14168

27. Liao J, Jin H, Li S, Xu L, Peng Z, Wei G, et al. Apatinib potentiates irradiation effect via suppressing PI3K/AKT signaling pathway in hepatocellular carcinoma. J Exp Clin Cancer Res (2019) 38. doi: 10.1186/s13046-019-1419-1

28. Wen S, Shao G, Zheng J, Zeng H, Luo J, Gu D. Apatinib regulates the cell proliferation and apoptosis of liver cancer by regulation of VEGFR2/STAT3 signaling. Pathol - Res Pract (2019) 215:816-21. doi: 10.1016/ j.prp.2019.01.021

29. Trotti A CA, Setser A, Rusch V, Jaques D, Budach V, Langer C, et al. CTCAE v3.0: development of a comprehensive grading system for the adverse effects of cancer treatment. Semin Radiat Oncol (2003) 13:176-81. doi: 10.1016/ S1053-4296(03)00031-6

30. Common Terminology Criteria for Adverse Events (CTCAE) v4.03. In: US Department of Health and Human Services, National Institute of Health, and National Cancer Institute.

31. Yang CH, Lin WC, Chuang CK, Chang YC, Pang ST, Lin YC, et al. Hand-foot skin reaction in patients treated with sorafenib: a clinicopathological study of cutaneous manifestations due to multitargeted kinase inhibitor therapy. $\mathrm{Br} \mathrm{J}$ Dermatol (2008) 158:592-6. doi: 10.1111/j.1365-2133.2007.08357.x

32. Zhu Y, Zhang X, Lou X, Chen M, Luo P, He Q. Vascular endothelial growth factor (VEGF) antibody significantly increases the risk of hand-foot skin reaction to multikinase inhibitors (MKIs): A systematic literature review and meta-analysis. Clin Exp Pharmacol Physiol (2018) 45:659-67. doi: 10.1111/ 1440-1681.12935

33. Autier J, Escudier B, Wechsler J, Spatz A, Robert C. Prospetive study of the cutaneous adverse effects of sorafenib, a novel multikinase inhibitor. Arch Dermatol (2008) 144:886-92. doi: 10.1001/archderm.144.7.886

34. Sirka CS, Sahu K, Pradhan S, Rout AN. Sorafenib-induced grade III hand-foot skin reaction with ulcerative dermatitis on scrotum, penis, and earlobe. Indian J Dermatol Venereol Leprol (2019) 85:623-6. doi: 10.4103/ijdvl.IJDVL_67_19

35. Strumberg D, Richly H, Hilger RA, Schleucher N, Korfee S, Tewes M, et al. Phase I clinical and pharmacokinetic study of the novel Raf kinase and vascular endothelial growth factor receptor inhibitor BAY 43-9006 in patients with advanced refractory solid tumors. J Clin Oncol (2005) 23:965-72. doi: $10.1200 / J C O .2005 .06 .124$

36. Jain L, Gardner ER, Figg WD, Chernick MS, Kong HH. Lack of association between excretion of sorafenib in sweat and hand-foot skin reaction. Pharmacotherapy (2010) 30:52-6. doi: 10.1592/phco.30.1.52

37. Lacouture ME, Wu S, Rober C, Atkins MB, Kong HH, Guitart J, et al. Evolving strategies for the management of hand-foot skin reaction associated with the multitargeted kinase inhibitors sorafenib and sunitinib. Oncologist (2008) 13:1001-11. doi: 10.1634/theoncologist.2008-0131

38. Sibaud V, Delord JP, Chevreau C. Sorafenib-induced hand-foot skin reaction: a Koebner phenomenon? Target Oncol (2009) 4:307-10. doi: 10.1007/s11523009-0127-8

39. Azad NS, Aragon-Ching JB, Dahut WL, Gutierrez M, Figg WD, Jain L, et al. Hand-foot skin reaction increases with cumulative sorafenib dose and with combination anti-vascular endothelial growth factor therapy. Clin Cancer Res (2009) 15:1411-6. doi: 10.1158/1078-0432.CCR-08-1141

40. Lai SE, Kuzel T, Lacouture ME. Hand-foot and stump syndrome to sorafenib. J Clin Oncol (2007) 25:341-3. doi: 10.1200/JCO.2006.08.9565

41. Miller KK, Gorcey L, McLellan BN. Chemotherapy-induced hand-foot syndrome and nail changes: a review of clinical presentation, etiology, pathogenesis, and management. J Am Acad Dermatol (2014) 71:787-94. doi: $10.1016 /$ j.jaad.2014.03.019

42. Kuang YH, Lu Y, Liu YK, Liao LQ, Zhou XC, Qin QS, et al. Topical Sunitinib ointment alleviates Psoriasis-like inflammation by inhibiting the proliferation and apoptosis of keratinocytes. Eur J Pharmacol (2018) 824:57-63. doi: 10.1016/j.ejphar.2018.01.048

43. Thomas SE, Dykes PJ, Marks R. Plantar hyperkeratosis: a study of callosities and normal plantar skin. J Invest Dermatol (1985) 85:394-7. doi: 10.1111/ 1523-1747.ep12277052

44. Mackenzie IC PG. Effect of frictional stimulation on the structure of the stratum corneum. In: R Marks, editor. Stratum Corneum. Berlin: Springer Berlin Heidelberg (1983). p. 153-70. doi: 10.1007/978-3-642-68682-5_17

45. Porta C, Paglino C, Imarisio I, Bonomi L. Uncovering Pandora's vase: the growing problem of new toxicities from novel anticancer agents. The case of sorafenib and sunitinib. Clin Exp Med (2008) 7:127-34. doi: 10.1007/s10238-007-0145-8

46. Zeng R, Xu H, Liu Y, Du L, Duan Z, Tong J, et al. miR-146a Inhibits BiofilmDerived Cutibacterium acnes-Induced Inflammatory Reactions in Human Keratinocytes. J Invest Dermatol (2019) 139:2488-96.e4. doi: 10.1016/ j.jid.2019.03.1161

47. Li T, Wei Z, Sun Y, Wang Q, Kuang H. Withanolides, Extracted from Datura Metel L. Inhibit Keratinocyte Proliferation and Imiquimod-Induced PsoriasisLike Dermatitis via the STAT3/P38/ERK1/2 Pathway. Molecules (2019) 24:2596. doi: 10.3390/molecules24142596

48. Feng Y, Zhou MY, Sun F, Kong Z, Wang J, Sun ZQ, et al. The inhibition effects of apatinib on cell proliferation, migration and apoptosis in esophageal 
carcinoma via Ras/Raf/MEK/ERK and JAK2/STAT3 pathways. Chin J Oncol (2019) 41:263-74. doi: 10.3760/cma.j.issn.0253-3766.2019.04.005

49. Wilhelm SM, Dumas J, Adnane L, Lynch M, Carter CA, Schutz G, et al. Regorafenib (BAY 73-4506): a new oral multikinase inhibitor of angiogenic, stromal and oncogenic receptor tyrosine kinases with potent preclinical antitumor activity. Int J Cancer (2011) 129:245-55. doi: 10.1002/ ijc. 25864

50. Zimmerman EI, Gibson AA, Hu S, Vasilyeva A, Orwick SJ, Du G, et al. Multikinase Inhibitors Induce Cutaneous Toxicity through OAT6-Mediated Uptake and MAP3K7-Driven Cell Death. Cancer Res (2016) 76:117-26. doi: 10.1158/0008-5472.CAN-15-0694

51. Omori E, Morioka S, Matsumoto K, Ninomiya-Tsuji J. TAK1 Regulates Reactive Oxygen Species and Cell Death in Keratinocytes, Which Is Essential for Skin Integrity. J Biol Chem (2008) 283:26161-8. doi: 10.1074/ jbc.M804513200

52. Anderson R, Jatoi A, Robert C, Wood LS, Keating KN, Lacouture ME. Search for evidence-based approaches for the prevention and palliation of hand-foot skin reaction (HFSR) caused by the mul- tikinase inhibitors (MKIs). Oncologist (2009) 14:291-302. doi: 10.1634/theoncologist.2008-0237

53. Grávalos C, Sanmartín O, Gúrpide A, España A, Majem M, Suh OHJ, et al. Clinical management of cutaneous adverse events in patients on targeted anticancer therapies and immunotherapies: a national consensus statement by the Spanish Academy of Dermatology and Venereology and the Spanish Society of Medical Oncology. Clin Transl Oncol (2019) 21:556-71. doi: 10.1007/s12094-018-1953-x

54. Peuvrel L, Dreno B. Dermatological toxicity associated with targeted therapies in cancer: optimal management. Am J Clin Dermatol (2014) 15:425-44. doi: 10.1007/s40257-014-0088-2

55. Shinohara N, Nonomura N, Eto M, Kimura G, Minami H, Tokunaga S, et al. A randomized multicenter phase II trial on the efficacy of a hydrocolloid dressing containing ceramide with a low-friction external surface for handfoot skin reaction caused by sorafenib in patients with renal cell carcinoma. Ann Oncol (2014) 25:472-6. doi: 10.1093/annonc/mdt541

56. Ai L, Xu Z, Yang B, He Q, Luo P. Sorafenib-associated hand-foot skin reaction: practical advice on diagnosis, mechanism, prevention, and management. Expert Rev Clin Pharmacol (2019) 12:1121-7. doi: 10.1080/ 17512433.2019.1689122

57. ClinicalTrails.gov Internet. South Korea Guro: Korea University Guro Hospital. Available at: https://clinicaltrials.gov/ct2/show/NCT03212625.
58. Duvic M, Asano AT, Hager C, Mays S. The pathogenesis of psoriasis and the mechanism of action of tazarotene. J Am Acad Dermatol (1998) 39:S129-133. doi: 10.1016/S0190-9622(98)70309-3

59. Yamamoto K, Ioroi T, Harada K, Nishiyama S, Nishigori C, Yano I. Safety and Efficacy of Bis-Glyceryl Ascorbate (Amitose DGA) to Prevent Hand-Foot Skin Reaction in Patients With Renal Cell Carcinoma Receiving Sunitinib Therapy: Protocol for a Phase I/II, Uncontrolled, Single-Arm, Open-Label Trial. JMIR Res Protoc (2019) 8:e14636. doi: 10.2196/14636

60. Yamamoto K, Shichiri H, Ishida T, Kaku K, Nishioka T, Kume M, et al. Effects of ascorbyl-2-phosphate magnesium on human keratinocyte toxicity and pathological changes by sorafenib. Biol Pharm Bull (2017) 40:1530-6. doi: 10.1248/bpb.b17-00386

61. Tian A, Zhou A, Bi X, Hu S, Jiang Z, Zhang W, et al. Efficacy of topical compound Danxiong granules for treatment of dermatologic toxicities induced by targeted anticancer therapy: a randomized, double-blind, placebo-controlled trial. Evid Based Complement Alternat Med (2017) 2017:3970601. doi: 10.1155/2017/3970601

62. Zhao C, Chen J, Yu B, Wu X, Dai C, Zhou C, et al. Effect of modified taohongsiwu decoction on patients with chemotherapy-induced hand-foot syndrome. J Tradit Chin Med (2014) 34:10-4. doi: 10.1016/S0254-6272(14)60047-9

63. Wang G, Jia L, Pei Y, Yu R, Gao Y, Deng C, et al. Clinical study for external Chinese herbal medicine LC09 treating hand-foot skin reaction associated with the antitumor targeted drugs. Medicine (2020) 99:e18849. doi: 10.1097/ MD. 0000000000018849

64. Naganuma A, Hoshino T, Ohno N, Ogawa Y, Murakami T, Horiguchi S, et al. $\beta$-Hydroxy- $\beta$-methyl Butyrate/L-Arginine/L-Glutamine Supplementation for Preventing Hand-Foot Skin Reaction in Sorafenib for Advanced Hepatocellular Carcinoma. In Vivo (2018) 33:155-61. doi: 10.21873/invivo.11452

Conflict of Interest: The authors declare that the research was conducted in the absence of any commercial or financial relationships that could be construed as a potential conflict of interest.

Copyright (c) $2021 \mathrm{Xia}$, Zhou, Luo, Zhang, Zhu and Gong. This is an open-access article distributed under the terms of the Creative Commons Attribution License (CC BY). The use, distribution or reproduction in other forums is permitted, provided the original author(s) and the copyright owner(s) are credited and that the original publication in this journal is cited, in accordance with accepted academic practice. No use, distribution or reproduction is permitted which does not comply with these terms. 